\title{
A Review of Approaches for Assessing Multimodal Quality of Service
}

\author{
Rhonda G. Phillips \\ Urban and Regional Planning Department, University of Florida \\ Martin Guttenplan \\ Systems Planning Office, Florida Department of Transportation
}

\begin{abstract}
Prompted by a need to respond to increasing traffic congestion, national, state, and local organizations have called for increased multimodal planning. This changing focus has added more complexity, data needs, and desire for supportive analytical tools to the transportation planning process overall. Multimodal performance methodologies are needed that can be readily applied. This article provides an analysis of existing methodologies to assess quality of service and related concerns for pedestrian, bicycle, and transit modes. It explores the methodologies in the context of supply-side considerations and provides considerations for their use. By placing transit-level service in line with pedestrian and bicycle, it brings all the modes together, making management easier.
\end{abstract}

\section{Introduction}

The Transportation Equity Act for the 21st Century (TEA-21) has recently called for communities to provide a multimodal transportation system in response to 
increasing traffic congestion. Pressure is increasing for local governments and planning organizations to respond by planning for multimodal transportation systems, yet tools to assist in these efforts are not readily apparent. The multimodal performance measures in many local congestion management plans are cursory at best-a confirmation of the lack of tools to help devise effective plans. The end result is that many communities do not utilize multimodal transportation options to ease congestion, as there are not many available methodologies to quantify the results or even measure the problem.

Quality of service (QOS) and related methodologies can function as tools to assist communities in planning multimodal transportation options. This article provides a summary of the types of QOS and related methodologies. While a few of these are not directly considered a QOS methodology, they provide a useful supply-side analysis, or in some cases, a relative demand potential perspective that is used in conjunction with supply approaches. Also, it should be noted that QOS literature for transit focuses on work by only a few researchers. The dominance of the transit level of service technique is apparent in the literature. While several attempts at pedestrian methodologies exist, they have not produced validated models as those for the bicycle mode; thus, the literature in this area is not as plentiful. The following section summarizes current approaches and relates them transit-level service.

\section{Multimodal QOS Concepts}

The words, "quality of service" are often used interchangeably with "level of service" (LOS) and "performance measures," yet caution is needed, as the three sets of terms are distinct. According to the Transit Capacity and QOS Manual (Kittelson et al. 1999d), the terms are simply defined as:

Quality of Service: The overall measure or perceived performance of service from the passenger's or user's point of view.

Level of Service: LOS is a range of six designated ranges of values for a particular aspect of service, graded from "A" (best) to " $F$ " (worst) based on a user's perception.

Performance Measures: A quantitative or qualitative factor used to evaluate a particular aspect of service. 
The primary differences between performance measures and service measures are (Kittelson, et al. 1999d: 5-2):

- Service measures represent the passenger's or user's point of view, while performance measures can reflect any number of points of view.

- Service measures should be relatively easy to measure and interpret in order to be beneficial to users.

- LOS grades (A-F) are typically developed and applied to service measures. The term has been used for more than 30 years in the Highway Capacity Manual.

Also, performance measures are typically viewed as the operator's point of view, are more vehicle-oriented, and incorporate various utilization and economic measures. For example, operator-based performance measures usually reflect ridership and economic factors while vehicle-based performance measures include such factors as roadway capacity and traffic signal delay time (Kittelson et al. 1999c:2). In contrast, service measures are person-oriented to reflect the passenger's or user's point of view.

To further illustrate the QOS concept, the case of transit is explored, using examples from the Transit Capacity and QOS Manual (Kittelson et al. 1999c, 1-38/ 39). Generally, a person is faced with a decision whether to use transit or an alternative mode. There are two parts to this decision process: (1) the potential passenger will assess the availability of transit and whether transit is an option for the trip; and (2) the potential passenger will compare the comfort and convenience of transit to alternative modes.

The following five conditions affect transit availability. All of these conditions must be met for the potential passenger to consider transit as an option for the trip: (1) transit must be provided near one's trip origin; (2) transit must be provided near one's destination; (3) transit must be provided at or near the times required; (4) information on using the transit service must be available; and (5) sufficient capacity must be provided. If these conditions are met, then transit is an option for the potential passenger; however, comfort and convenience issues are then considered. If these factors compare favorably with competing modes, then transit will be used. Some of the comfort and convenience factors affecting transit quality are: reliability of the transit service (time required to arrive at their destinations); total door-to-door travel time, as compared with alternative modes; costs of using the transit service, compared with alternative modes; safety and security of using the 
transit service, including accessing transit stops; passenger amenities provided; appearance and comfort of transit facilities and stops; and passenger loads on the transit vehicles (Kittelson et al. 1999d: 1-39).

Any of these factors (and others identified by local transit systems operators and transportation planners) can be analyzed for a particular transit stop, route segment, or an entire system to generate a QOS assessment. LOS measures, typically the $A$ through $F$ range, can be applied at this point. However, it is important for transit system planners and operators not to focus entirely on the LOS range calculations as a variety of other factors influence QOS that may not readily lend themselves to an "A-F" categorization.

\section{Current Approaches}

Difficulties are reported by both users and researchers with many of the existing methodologies used for measuring multimodal performance (Phillips, Karachepone, and Landis 2001). The difficulties are primarily due to the limited scope of factors imposed by these methodologies. For example, the Highway Capacity Manual (Transportation Research Board 1985) defines performance measures for bicycle and pedestrian environments simply as the degree of discomfort to the user due to overcrowding of the facilities. However, this measure may apply to only a small percentage of collector and arterial networks throughout urban areas; thus its applicability is severely limited. Other measures from the user's point of view to assess QOS are not standardized, or routinely utilized, leaving transportation planners with little or no feasible methodologies to use.

Similarly, much of the current transit QOS methodological approach follows the Highway Capacity Manual guidelines of evaluating the performance of the transit trip only. Other factors, such as transit accessibility, including how the user accesses the transit vehicle, are rarely included. For example, many transit stops do not have adequate amenities, such as sidewalk access; other areas have extremely long waiting times (headways) yet these areas are considered to have transit service. The obstacles the user must overcome are rarely considered in this type of methodological approach, leaving an inadequate and unclear assessment of transit's quality of service. Solutions to these obstacles can be integrated into pedestrian and bicycle planning as well, supporting all three modes.

Until recently, traditional concepts applied to highway and roadway policy, planning, and design have been superimposed to try to fit the needs of multimodal planning. Rarely has this worked to the extent that effective QOS methodologies 
are utilized to support planning and design for bicycle, pedestrian, and transit modes. As part of the overall transportation planning process, considerations for multimodal facilities have often been lacking due to the quiet nature and lack of knowledge of bicycle and pedestrian modes, in particular. For example, low trip volume, low space requirements as compared with motor vehicles' needs, and the inability of some travel demand models to account for these trips often commands less attention than other modes (Burrell 1994/95). Methodologies and tools are needed that can bring the level of analysis for multimodal to the same degree of confidence and usability as that for highway and roadway planning, yet take into account the distinct needs of multimodal planning. Bringing together the pedestrian, bicycle, and transit modes makes management easier at the local and municipal planning organization (MPO) level.

QOS methodologies are considered supply-side assessments-in other words, evaluation of existing facilities (Cambridge Systematics 1998a, b, c; Landis et al. 1996). Thus, past assessments have often focused on factors such as overcrowding of facilities and transit vehicle performance, or the quality of supply of multimodal facilities. Supply-side assessments do not predict or estimate future demand. However, they are invaluable in providing information for decision making regarding investments in improved or new multimodal facilities. They are indicators of the quality and benefits to users-information that can be used to guide or justify provision of additional facilities. Quality norms and perceptions of quality are essential to effective transportation planning; as described by Pettina (1991), quality can be assessed by usage, experience of the trip, and future values. Usage is determined by travelling time; experience is determined by safety and comfort; and future value is mostly determined by maintenance.

Comparatively, demand-side methods are used to generate quantitative estimates of demand for multimodal facilities. A variation of demand models are relative demand potential methodologies, those methods that assess the potential demand levels rather than predict actual demand. Supply-side assessments can be used in tandem with some of the demand-side methods, especially when demand is associated with the quality of existing facilities. For example, the City of Olympia, Washington, is considering measuring transit LOS through assessing the latent demand for transit service-basically how many people want to travel through a corridor or segment, a demand estimation technique (Lazar 1998). By combining this with more traditional transit LOS indicators, the City hopes to generate information and direction for complying with the Washington Growth Management 
Act stipulation that transportation systems be measured and assessed. There are numerous demand models in existence. ${ }^{1}$ The focus of this article however is on supply-side methods.

\section{Reviews of Methodologies}

\section{Environment Factors for Bicycle, Pedestrian, and Transit Modes}

Supply-side approaches for measuring the quality of an area's bicycle and pedestrian characteristics typically are used in conjunction with regional travel models. While substantial field data collection is required to develop environment factor ratings for local application (Antonakos 1994), the factors are generally relevant to a variety of regions and area types (Cambridge Systematics, Inc. 1998b). Environment factors can also be used for predicting transit trips as well as for bicycle and pedestrian modes because the quality of the pedestrian environment can influence transit selection. A "Transit Friendliness Factor" was developed for the Triangle Transit Authority in Raleigh, North Carolina, to predict automobile versus transit choice (Evans et al. 1997). Four elements were rated (on a scale of one to five): sidewalks, street crossings, transit amenities, and proximity to destinations. It was reported that including the transit friendliness factors greatly improved the model's ability to predict automobile versus transit trip selection (Cambridge Systematics, Inc. 1998a). These transit friendliness factors are directly related to pedestrian and bicycle mode planning as they are interrelated and support each other.

Portland, Oregon, was one of the first areas to develop a pedestrian environment factor (PEF) system, incorporated with its regional travel model. Portland's PEF includes: sidewalk availability, ease of street crossing, terrain, and connectivity of the street and sidewalk system (Cambridge Systematics, Inc. 1998a and 1998b). The factors are ranked, with points ranging from 0 to 12; bicycle factors are added for an additional range of 0 to 15 . Portland has reported success with improvements for predicting automobile versus pedestrian and bicycle mode split. Also, the significance of the scoring system is that the higher the PEF score, the more likely people choose walking, bicycling, or transit over automobile usage. In other words, there was a measurable relationship between the quality of the pedestrian environment and the travel mode choices being made (Parsons Brinckerhoff Quade and Douglas, Inc. et al. 1993).

This relationship is powerful support for integrating pedestrian environment analysis into transportation planning efforts. For example, in the 1970s communities 
began to realize that for transit systems to operate effectively, conditions such as high-speed traffic, wide streets, and narrow sidewalks that make it difficult to operate convenient service for riders must be addressed. Instead of relying on transportation agencies to make decisions from the top down, communities have encouraged a more integrated process of merging traffic and transit concerns with development and environmental concerns. This livable community approach is detailed in the Transit Cooperative Research Program Report 33 (1998:3):

For the transit user, better management and design of streets (and other conditions) not only can improve reliability of service-by reducing the competition for street space among cars, buses, or light rail vehicles-but can also make it safer and more accessible for transit patrons....(these approaches) can be combined with other transit strategies to realize even greater social and economic impacts, whether it be revitalizing a downtown, restoring cohesiveness to a community, or creating new development opportunities.

Further, some travel demand methods are enhanced by incorporating pedestrian environment analysis (Turner et al. 1998). By merging "supply" with demand analysis to provide a more complete analysis of issues for bicycle, pedestrian, and transit facilities, cities are able to implement a more holistic or integrated approach to transportation planning. Other areas have followed Portland's lead, applying environment factors to regional travel models. These areas include Washington, D.C. (Chesapeake Bay Foundation 1996) and Sacramento, California. Montgomery County, Maryland, developed a different pedestrian and bicycle environment factor (PBEF) that includes five elements: amount of sidewalks, land-use mix, building setbacks, transit-stop conditions, and bicycle infrastructure (Cambridge Systematics, Inc. 1998a and 1998b). Montgomery County reports a significant improvement in the performance of its regional travel model by including the pedestrian and bicycle environment factor.

\section{Compatibility Measures for Bicycle, Pedestrian, and Transit Modes}

Another type of supply-side or quality of supply approach is compatibility analysis. There are several types of compatibility approaches: pedestrian stress level and LOS assessments, bicycle stress level and LOS assessments, and transit LOS assessments. Pedestrian compatibility approaches measure the quality of existing facilities for pedestrian travel, rather than forecasting demand for expanded facilities. Pedestrian approaches and methods are considerably less developed than for bi-

cycle or transit modes (Dixon 1996; Khisty 1994; Landis 1998b). Yet the value of 
assessing pedestrian facilities ranks high as an important tool in improving the transportation planning process (FDOT 1992). Khisty (1994:49) points out several applications of pedestrian compatibility approaches: results can be used as a tool to guide decision-makers in evaluating quality of facilities beyond quantitative measures of flow, speed, and density; results identify ideal benchmarks; can be used as a planning tool to develop future routes; and results can be used in budgeting funds for improvements. Although pedestrian approaches and methodologies are still "emerging," the inclusion of the pedestrian element has long been recognized by some as vitally important, with the need to fully integrate the process of pedestrian facility planning into other planning activities such as comprehensive planning, subarea planning, and site plan review (JKL \& Associates et al. 1987).

As part of a congestion management plan, the City of Gainesville, Florida, incorporated LOS measures for pedestrian facilities. This methodology represents one of the more comprehensive approaches taken to date. A point system, ranging from 1 to 21 was used to evaluate actual roadway corridors for pedestrian suitability. Scores were then converted into a LOS range from A to $F$. The following criteria were used: pedestrian facility type (dominant facility type, sidewalk width, offstreet parallel alternative facility); conflicts (number of driveways and sidewalks, pedestrian signal delay times, reduced turn-conflict implementations, crossing widths, speed of traffic, medians present); amenities in right-of-way (buffers, benches or pedestrian-scale lighting, shade trees); maintenance; and TDM and multimodal support (Dixon 1996).

Gainesville's method focuses on pedestrian facility conflicts, amenities, maintenance, and several other factors. Another pedestrian LOS and stress level method was developed by Mozer (1998). This approach focuses on facility design with speed, outside lane width, and volume as the primary criteria. Both methods have not been designed to be incorporated with travel demand models, in contrast to the environment factors approach. Similar to Dixon's checklist of pedestrian travel conditions, the City of Fort Collins, Colorado, provided a LOS standards for five areas of concern: directness, continuity, street crossings, visual interest and amenity and security. For each of these areas, brief descriptions were given to provide a scale, with LOS A representing the best pedestrian environment through level-of service $F$ representing the worst pedestrian environment. It attempts to apply particular LOS standards to geographical areas of the Fort Collins community, determining a minimal LOS standard for that area. For example, the downtown 
business district, where compactness is an asset, would score highly on all LOS thresholds.

A different method developed by Romer and Sathisan (1997) combined factors to analyze entire pedestrian systems, rather than individual factors. Using the key variables in each of the three method elements (sidewalks, corner areas, and crosswalks), a balanced approach is attempted to provide an overall LOS assessment. A method used in Europe assesses existing quality against desired quality, with less quantitative focus than LOS methodologies (Centre for Research and Contract Specialization in Civil Engineering 1993).

At the behest of the Hillsborough County (Florida) Metropolitan Planning Organization, Sprinkle Consulting, Inc. assisted in the formation of a community-wide pedestrian system plan. With the expressed purpose of designing a mathematical model to quantify the perceived safety of the pedestrian environment, the Sprinkle methodology provided Hillsborough County with a method in which roadways could be prioritized for sidewalk construction and sidewalk retrofit. In the mid 1990s Hillsborough County searched for a "blueprint" in which to upgrade its pedestrian environment. Sprinkle's criteria for evaluating the pedestrian environment included six performance factors (of which three were considered significant) and were rigorously tested in Hillsborough County (Hillsborough County Metropolitan Planning Organization 1999). The factors, determined by group consensus, include:

1. lateral separation between pedestrians and motor vehicle traffic;

2. outside (motor vehicle) lane volume;

3. effect of (motor vehicle) speed;

4. roadway (transverse) crossing inconvenience;

5. environmental amenities; and

6. sidewalk surface condition.

Designed to assess walking conditions (with or without the presence of sidewalks), the evaluation was based on a mathematical approach called the Roadside Pedestrian Condition model (RPC). Hillsborough County streets were given LOS letter grades, ranging from A to F. Hillsborough County used this LOS ranking system to assist in evaluating and prioritizing its roadways for sidewalk retrofit and construction. 
A variety of bicycle stress level and LOS assessments (Eddy 1996; Turner et al. 1997) exists, including the Bicycle Compatibility Index $(\mathrm{BCl})$ developed for the Federal Highway Administration. The $\mathrm{BCl}$ is an attempt to promote a methodology that can be widely applied by transportation planners and engineers to determine how compatible a roadway is for allowing operation of both bicycle and motor vehicle traffic (Cambridge Systematics, Inc. 1998c). It incorporates roadway variables with those bicyclists typically use to assess the "bicycle friendliness" of a roadway (Harkey et al. 1998a and b). The $\mathrm{BCl}$ uses several independent variables for the model, including: presence of bicycle lane or paved shoulder and width, presence of a parking lane with more than 30 percent occupancy, type of roadside development, $85^{\text {th }}$ percentile speed of traffic, curb-lane width, curb-lane volume, and other lane volume. The method has good validation techniques that improve its effectiveness and is considered an improvement by some researchers (Cambridge Systematics 1998a) upon earlier stress level work of Sorton and Walsh (1994a) and the Geelong Planning Committee (1978).

Sorton and Walsh (1994a and b) provided an earlier model to determine the stress level for bicyclists and bicycle compatibility of roadways. Building on three primary variables (curb-lane speed, curb-lane width, and peak hour volume), a bicycle LOS measure was developed. However, the model has been criticized for leaving out crucial factors, such as pavement conditions, roadways with bicycle lanes, and intersection density and volume (Cambridge Systematics 1998a).

In addition to the pedestrian compatibility approach developed by Gainesville, Florida (Dixon 1996), a bicycle LOS measure was also developed and implemented. The LOS developed is more comprehensive than some of the earlier efforts, and reflects an improvement upon the works by Davis (1987), Epperson (1994), and Sorton and Walsh (1994a). A point system was developed to evaluate roadway corridors, and then converted into an LOS range of $A$ to $F$. Measures for the bicycle LOS included: basic facilities (outside lane width, off-street facilities); conflicts (driveways and sidestreets, barriers, no on-street parking, medians present, unrestricted sight distance, intersection implementation); speed; motor vehicles; maintenance; and transportation demand management multimodal facilities.

The Interaction Hazard Score model was developed several years ago to provide a supply-side measure of the on-road bicycling environment (Landis 1994 and 1996). The model utilizes existing traffic and roadway data and variables to estimate the perceived hazard of bicycle and automotive compatibility. The interaction model was developed to overcome deficiencies of earlier models, such as Florida's Road- 
way Condition Index (Epperson 1994), the Segment Condition Index, and the Davis model's Bicycle Safety Index Rating (Davis 1987; Horowitz 1996).

Several factors influence a bicyclist's perception of interaction hazard: speed of the motor vehicle traffic, traffic characteristics, proximity of the bicyclist to motor vehicle traffic, and the volume of the motor vehicle traffic (Landis 1996). Cities throughout the United States utilize the interaction model, often translating the results into LOS categories for bicycle facility planning. This practice has prompted the acceptance of the perception of hazard as a valid LOS measure.

The Interaction Hazard Score model led to the development of the Bicycle Level of Service model (BLOS), designed to quantify the level of comfort or threat of roadway hazard that, in theory, is connected with the use of roadways. The model is statistically based, and reflects the effect on bicycle compatibility due to factors such as traffic volume, pavement surface conditions, motor vehicle speed and type, on-street parking, bike lane widths and striping, and roadway width (Landis 1998a). The BLOS model differs from others in that it provides a theoretical basis for testing. A study measuring the responses of 150 bicyclists in Tampa, Florida, was used as the baseline data for developing the model and software, which according to the developer, can be applied to the majority of roadways in the United States (Landis 1998). The BLOS is based solely on human responses to measurable roadway and traffic stimuli (Landis et al. 1996:120), rather than estimations or proxies as are some of the other stress level approaches.

Another approach at assessing bicycle facilities was formulated by Nelson and Allen (1997) to analyze existing data for 18 U.S. cities (Goldsmith 1994). The research was driven by the question: Does providing bicycle facilities mean that people will use them? In other words, this research incorporates a supply-side approach to assessing facilities. A regression equation was used to test the research question with somewhat inconclusive results. The most statistically valid finding was the strength of the relationship between the miles of bicycle paths per 100,000 residents and the percentage of commuters using them-as the miles of paths increased, so did usage (as was expected). The researchers use these results to promote the theory that a latent demand for bicycle facilities may only be tapped by providing bicycle facilities, as suggested earlier by researchers at the University of North Carolina Highway Safety Research Center (1994). 


\section{Transit Measures}

Existing measures of transit availability - a key measure of transit quality-typically overstate the degree to which transit service is available at a location. To overcome this, the Florida Department of Transportation contracted with Kittelson \& Associates (1999a) to develop the FDOT Transit Level of Service (TLOS) indicator to address both the spatial and temporal aspects of transit availability. The TLOS indicator, which is software-based, uses percent person-minutes served, defined as the average percent of time that people have transit service available (over time) and accessible (spatially) to them (Kittelson \& Associates 1999a and b).

An even more extensive QOS measure was presented in The Transit Capacity and QOS Manual (Kittelson \& Associates, Inc. 1999d), the transit counterpart to the Highway Capacity Manual. This measure is broader than the Transit Level of Service indicator because it addresses factors other than accessibility and modes other than fixed-route transit; it is more generalized because it requires less detailed information, although it produces less precise results. However, the Transit Level of Service indicator is compatible with this national QOS framework. The measures used in the Transit Capacity and QOS framework are:

- Availability: Transit stop (frequency, availability, passenger loads), route segment (hours of service, accessibility), system (service coverage, \% person-minutes served indices);

- Quality: Transit stop (passenger loads, amenities, reliability), route segment (reliability, travel speed, transit/auto travel time), and system (transit/auto travel time, travel time, safety) (Kittelson \& Associates 1999a and d).

\section{Conclusion}

All of the methods explored represent varying degrees of improvement over past efforts. Each approach offers contributions and often one or more approaches are used to provide a more comprehensive assessment. With improvement, all are tools to bring transit level service "to the table" so that pedestrian, bicycle, and transit can be considered together.

A shortcoming of current methodologies is the lack of consideration for parallel paths, trails, or sidewalk systems that are used or could be used, as transportation corridors. If safe and relatively direct paths can be provided away from vehicular traffic, then it is likely that bicycle, pedestrian, and transit mode choices would 
increase. Urban trails and other alternative routes may help create a shift in demand from vehicular usage to pedestrian and bicycle modes, yet little research has been conducted in this area. Increasing bicycle and pedestrian modes will enhance transit level service as all three modes interface.

Advances made in assessing conditions for nonautomobile transportation can help in the routine accommodation of these modes in transportation systems. Local governments can now set quantifiable standards for levels of service. Some local governments are already doing this in the areas surrounding schools, parks, and other areas with high demand for nonautomobile transportation. ${ }^{2}$ In closing, the work summarized in this article should help bring legitimacy to providing for all modes of transportation and provide information to governments concerned with multimodal quality of service. By strengthening all modes, transit level service is improved as well.

\section{Endnotes}

${ }^{1}$ For examples of demand-side models see: comparison studies (Wigan et al. 1998); aggregate behavior studies (Nelson and Allen 1997; Ridgway 1995); discrete choice models (Loutzenheiser 1997; Kitamura et al. 1997; Noland and Kunreuther 1995; Taylor and Mahmassani 1996); regional travel models (Cambridge Systematics, Inc. 1998b; Hunt et al. 1998; Replogle 1996; Replogle 1995; Stein 1996); and sketch plan methods (Ercolano et al. 1995; Ercolano 1997; Matlick 1996).

2 Florida DOT has adopted a simplified methodology using default assumptions, which integrates the SCI Bicycle LOS, Pedestrian LOS, Transit Capacity and Quality of Service Manual and the Highway Capacity Manual. By integrating these into a stand-alone interactive software product, it is now possible to conduct what-iftype analysis to see how proposed changes in the roadway environment affect each of the modes. This should become a powerful tool for alternatives analysis in preliminary engineering studies. Florida DOT has also been expanding its initial multimodal Q/LOS research to include intersection, transit stop, corridors, pedestrian mid-block crossing, and areawide analysis. The most up-to-date information on this work can be found at the Florida DOT's Level of Service webpage: http://www11.myflorida.com/planning/systems/sm/los/default.htm. 
Journal of Public Transportation, Vol. 6, No. 4, 2003

\section{References}

Antonakos, Cathy. 1994. Environmental and travel preferences of cyclists. Transportation Research Record 1438:25-36.

Burrell, Donald. 1994/95. Making bicycle and pedestrian planning work, A supply and demand approach. Transportation Planning XXI(4): 1, 10-14.

Cambridge Systematics, Inc., Bicycle Federation of America, and Michael Replogle. 1998a. Guidebook on methods to estimate nonmotorized travel. Cambridge, MA.

Cambridge Systematics, Inc. 1998b. Supporting documentation on methods to estimate nonmotorized travel. Cambridge, MA.

Cambridge Systematics, Inc. 1998c. Forecasting bicycle and pedestrian travel. Workshop presented at the ProBike/ProWalk '98, Santa Barbara, CA.

Centre for Research and Contract Standardization in Civil Engineering. 1993. Sign up for the bike, design manual for a cycle-friendly infrastructure. The Netherlands.

Chesapeake Bay Foundation, Environment Defense Fund. 1996. A network of livable communities: Evaluation travel behavior effects of alternative transportation and community design for the national capital region. Washington, D.C.

Davis, Jeff. 1987. Bicycle safety evaluation. Auburn, AL: Auburn University.

Dixon, Linda B. 1996. Bicycle and pedestrian level-of-service performance measures and standards for congestion management systems. Transportation Research Record 1538, 1-9.

Eddy, Niles. 1996. Developing a level of service for bicycle use. Bicycle Federation of America-Pedestrian Federation of America: 310-314.

Epperson, Bruce. 1994. Evaluating suitability of roadways for bicycle use: Toward a cycling level-of-service standard. Transportation Research Record 1438:9-16.

Ercolano, James, Jeffrey Olson, and Douglas Spring. 1995. Sketch-plan method for estimating pedestrian traffic for Central Business Districts and suburban growth corridors. Transportation Research Record 1578:38-47.

Ercolano, James, Jeffrey Olson, and Douglas Spring. 1997. Sketch plan method for estimating pedestrian traffic. New York: Transportation Planning, Highway 
Safety and Traffic Engineering Division, New York State Department of Transportation.

Evans, John E., IV., Vijay Perincherry, and G. Bruce Douglas, III. 1997. Transit friendliness factor: An approach to quantifying the transit access environment in a transportation planning model. Presented at the 1997 Transportation Research Board Annual Meeting, Paper \#971435.

Florida Department of Transportation. 1992. Florida Pedestrian Plan. Tallahassee, FL: Florida Department of Transportation, February.

Geelong Planning Committee. 1978. Geelong Bikeplan. Geelong, Australia.

Goldsmith, S. A. 1994. National bicycling and walking study, Case Study No. 1: Reasons why bicycling and walking are and are not being used more extensively as travel modes. FHWA-PD-92_041: FHWA, U.S. Department of Transportation.

Harkey, David, Donald Reinfurt, Matthew Knuniman, Richard Stewart, Alex Sorton. 1998a. Development of the Bicycle Compatibility Index: A level of service concept. Chapel Hill, NC: FHWA-RD-98-072, University of North Carolina.

Harkey, David, Donald Reinfurt, and Alex Sorton. 1998b. The Bicycle Compatibility Index: A level of service concept, implementation manual. Chapel Hill, NC: FHWA-RD-98-095, University of North Carolina.

Hillsborough County Metropolitan Planning Organization. 1999. The Hillsborough County MPO pedestrian system plan. Tampa, FL.

Horowitz, Mark. 1996. Overview of three roadway condition indexing models for bicycle transportation. ProBike ProWalk 96: Forecasting the Future. Bicycle Federation of America/Pedestrian Federation of America, pp. 303-309.

Hunt, J. D., A. T. Brownlee, and L. P. Doblanko. 1998. Design and calibration of the Edmonton transport analysis model. Presented at the 1998 Transportation Research Board Annual Meeting, Paper \#981076.

JKL \& Associates, Center for Applied Research, RTKL Associates, Inc. 1987. Planning and implementing pedestrian facilities in suburban and developing rural areas. National Cooperative Highway Research Program Report 294A. Transportation Research Board.

Khisty, C. Jotin. 1994. Evaluation of pedestrian facilities: Beyond the level-of-service concept. Transportation Research Record 1438:45-50. 
Kitamura, Ryuichi, Patricia Mokhtarian, and Laura Laidet. 1997. A micro-analysis of land use and travel in five neighborhoods in the San Francisco Bay Area. Transportation 24(2).

Kittleson \& Associates, Inc. 1999a. Development of a transit level of service (TLOS) indicator. Ft. Lauderdale, FL: Kittleson \& Associates, Inc.

Kittleson \& Associates, Inc. 1999b. Transit planning and operations techniques. Ft. Lauderdale, Florida.

Kittleson \& Associates, Inc., URS Greiner Woodward Clyde, Inc., and REP Associates, Inc. 1999c. Transit level of service (TLOS) indicator. Ft. Lauderdale, FL.

Kittleson \& Associates, Inc., Texas Transportation Institute, and Transport Consulting Limited. 1999d. Transit capacity and QOS manual. Transit Cooperative Research Program,Washington, D.C. January.

Landis, Bruce. 1994. "Bicycle Interaction Hazard Score: A Theoretical Model. Transportation Research Record 1438:3-8.

Landis, Bruce. 1996. Bicycle system performance measures. ITE Journal: 18-25.

Landis, Bruce. 1998a. Bicycle suitability evaluation of roadways. Lutz, FL: Sprinkle Consulting, Inc.

Landis, Bruce. 1998b. Level of service methodology: The roadside pedestrian environment. Transportation Research Board Paper No. 990570. Sprinkle Consulting, Inc., Lutz, FL.

Landis, Bruce, and Jennifer Toole. 1996. \#70 Using the latent demand score model to estimate use. Forecasting the Future, ProBike/ProWalk 96. Bicycle Federation of America-Pedestrian Federation of America.

Landis, Bruce, Venkat Vattikuti, and Michael Brannick. 1996. Real-time human perceptions toward a bicycle level of service. Transportation Research Record 1578:119-126.

Lazar, Jim. 1998. Toward a multimodal approach to measuring transportation level of service under the Washington Growth Management Act. Olympia, WA: Lazar.

Loutzenheiser, David. 1997. Pedestrian Access to Transit: A Model of Walk Trips and Their Design and Urban Form Determinants Around BART Stations. Transportation Research Board, $76^{\text {th }}$ Annual Meeting, Washington, D.C. 
Matlick, Julie M. 1996. If we build them, will they come? \#69 Forecasting Pedestrian Use and Flows, Forecasting the Future. Bicycle Federation of America - Pedestrian Federation of America, Pro Bike/Pro Walk '96, pp. 315-319.

Mozer, David. 1998. Calculating multimodal levels-of-service. International Bicycle Fund, www.ibike.org/los.htm:1-8.

Nelson, Arthur C., and David Allen. 1997. If You Build Them, Commuters Will Use Them: Cross-Sectional Analysis of Commuters and Bicycle Facilities. City Planning Program, Georgia Institute of Technology, presented to the Transportation Research Board, $76^{\text {th }}$ Annual Meeting, Washington, D.C.

Noland, Robert, and Howard Kunreuther. 1995. Short-run and long-run policies for increasing bicycle transportation for daily commuter trips. Transport Policy 2(1).

Parsons Brinckerhoff Quade and Douglas, Inc., Cambridge Systematics, Inc., and Calthorpe Associates. 1993 Making the land use transportation air quality connection - The pedestrian environment. Vol. 4a. Portland, OR: Thousand Friends of Oregon.

Pettina, Andre. 1991. Can big cities be bicycle friendly cities? In Still More Bikes Behind the Dikes. The Netherlands: Centre for Research and Contract Standardization in Civil and Traffic Engineering.

Phillips, Rhonda, John Karachepone, and Bruce Landis. 2001. Multimodal QOS project. Gainesville, FL: University of Florida.

Replogle, Michael. 1995. Integrating pedestrian and bicycle factors into regional transportation planning models: Summary of the state-of-the-art and suggested steps forward. Environmental Defense Fund, pp. 1-21.

Replogle, Michael. 1996. Inside the black box: An insider's guide to transportation models. ProBike ProWalk 96, Bicycle Federation of America/Pedestrian Federal of America, pp. 276-280, September.

Ridgway, Matthew D. 1995. Projecting Bicycle Demand: An Application of Travel Demand Modeling Techniques to Bicycles. 1995 Compendium of Technical Papers, Institute of Transportation Engineers $65^{\text {th }}$ Annual Meeting, pp. 755785.

Romer, Richard T., and Shashi Sathisan. 1997. Integrated systems methodology for pedestrian traffic flow analysis. Transportation Research Record 1578. 
Sorton, Alex, and Thomas Walsh. 1994a. Bicycle stress level as a tool to evaluate urban and suburban bicycle compatibility. Transportation Research Record 1438:17-24.

Sorton, Alex. 1994b. Urban and Suburban Bicycle Compatibility Street Evaluation Using Bicycle Stress Level. Presented at the $73^{\text {rd }}$ Annual Meeting of the Transportation Research Board, Washington, D.C.

Stein, William R. 1996. Pedestrian and bicycle modeling in North America's urban areas: A survey of emerging methodologies and MPO practices. Thesis, Georgia Institute of Technology.

Taylor, Dean, and Hani Mahmassani. 1996. Analysis of stated preferences for intermodal bicycle-transit facilities. Transportation Research Record 1556.

Transit Cooperative Research Program. 1998. Transit-Friendly Streets: Design and Traffic Management Strategies to Support Livable Communities. TCRP Report 33. Transportation Research Board.

Transportation Research Board. 1985. Highway Capacity Manual. Washington, DC: National Research Council.

Turner, Shawn, Gordon Shunk, and Aaron Hottenstein. 1998. Development of a methodology to estimate bicycle and pedestrian travel demand. College Station, TX: Texas Transportation Institute.

Turner, Shawn, C. Scott Shafer, and William P. Stewart. 1997. Bicycle suitability criteria for state roadways in Texas. College Station, TX: Texas Transportation Institute.

University of North Carolina Highway Safety Research Center. (1994) A Compendium of Available Bicycle and Pedestrian Trip Generation Data in the United States. Federal Highway Administration, FHWA-PF-95-009.

Wigan, Marcus, Anthony J. Richardson, and Paris Brunton. 1998. Simplified estimation of demand for nonmotorized trails using GIS. Transportation Research Board, Preprint \#981203. 


\section{About the Authors}

Rhonda G. Philuips (rhondap@ufl.edu) is director of the Center for Building Better Communities at the University of Florida where she teaches economic and community development in the Urban and Regional Planning Department. She holds dual professional certifications in planning (AICP) and economic development (CED).

MARTIN GutTenPLAN (martin.guttenplan@dot.state.fl.us) is a manager in the Florida Department of Transportation's Systems Planning Office where he conducts a variety of projects for multimodal integration in communities throughout Florida. 